\title{
Confidence in the police in Scotland: Trends in Scottish Crime and Justice Survey responses, 2012/13-2017/18
}

\author{
Briefing Note by the Understanding Inequalities Project Team
}

Dr Ben Matthews, Professor Susan McVie, Dr Kath Murray and Dr Paul Norris

$13 / 05 / 2020$

\section{Key findings}

1. Using a 'global' measure of confidence in the police from the Scottish Crime and Justice Survey, the majority of people in Scotland report that the police in their local area are doing a good or an excellent job.

2. Confidence in the police in Scotland is at a broadly similar level to that in England and Wales, and higher than that in Northern Ireland.

3. Confidence in the police in Scotland has declined since $2012 / 13$, from around $63 \%$ to $59 \%$ in 2017/18. This contrasts with a rise in confidence in Northern Ireland, but there has also been a decline in confidence in the police in England and Wales.

4. In Scotland, this trend is mostly driven by a fall in confidence amongst those who were the most confident in the police, with little change amongst those who were already lower in confidence.

5. Specifically, there were:

- Declines in global confidence amongst non-victims, with no evidence of change amongst victims of crime.

- No evidence of change in global confidence amongst those living in Scotland's $15 \%$ most deprived neighbourhoods, but a fall in other areas.

- A decline in global confidence amongst over 65s, with little evidence of a clear trend amongst other age groups.

- A substantial decline in global confidence amongst men, with only a slight decline amongst women.

- Falls in global confidence amongst people living in Police Scotland North and East Command Areas, but little evidence of a fall amongst those living in the West Command Area.

6. There is a large and fairly consistent reduction in confidence in the police amongst those aged over 65 across all three Police Scotland Command Areas, suggesting that a national strategy may be needed to improve this.

7. Confidence in the police has reduced more amongst non-victims of crime in the East and North Command Areas, compared to the West, where it was already lower. Again, this suggests that a national strategy may be needed to improve confidence.

8. More detailed analysis of confidence in the police across these groups could be provided, although this would require combining data together across years (so loss of trend information) and more complex statistical modelling. 


\section{Introduction}

This report presents a high-level analysis of trends in overall confidence in the police in Scotland between 2012/13 and 2017/18 using data from four sweeps of the Scottish Crime and Justice Survey (SCJS) conducted in 2012/13, 2014/15, 2016/17 and 2017/18.

\section{Data and Method}

We measure confidence in the police using the SCJS question: 'Taking everything into account, how good a job do you think the police in this area are doing?'. We refer to this as a 'global' measure of confidence in the police (see Appendix A for discussion of this terminology and wider issues when measuring confidence in police).

We take the percentage of respondents who answered "Good" or "Excellent" to this question over the four sweeps of the SCJS as our indicator of global confidence in the police in Scotland. We use the Scottish Government's survey weights to gross up responses to give an estimate of confidence in the police amongst the Scottish population as a whole.

We start by presenting trends in the estimate of global confidence in the police for all SCJS respondents. We also put this in context by comparing it to trends in global confidence in England and Wales over the same time period. We then present trends in confidence in the police in Scotland across five categories:

- Whether a person was a victim of crime or not;

- Whether a person lives in one of the $15 \%$ most deprived neighbourhoods in Scotland;

- Age;

- Sex;

- $\quad$ Police Scotland Command Area.

Finally, we break these data down further into sub-types to examine confidence in the police within the three Police Scotland Command Areas according to age and experience of victimisation. The results of this more detailed breakdown are only tentative because dividing the dataset further reduces sample sizes to the extent that trend estimates become unreliable. We could do this, if required, by combining the data together across years, but this would lose the element of change over time.

Note that because the measures of global confidence in the police amongst the Scottish population are estimated from a survey, there is some degree of 'error' around the estimates. We have highlighted the degree of error in the graphs below using shading to represent a 95\% confidence interval around the estimates. This means we are $95 \%$ confident that the 'true' level of confidence in the police fell within these limits. 


\section{Five year trend in overall confidence in the police}

Figure 1 shows the estimated percentage of the Scottish population who thought that the police in their area were doing a 'good' or 'excellent' job. This shows that global confidence in the police in Scotland declined from around 63\% to 60\% between 2012/13 and 2014/15, and then declined again to around 59\% between 2016/17 and 2017/18.

Because the confidence intervals for the estimate from 2012/13 and 2017/18 do not overlap, we can say that this reduction in global confidence is 'statistically significant'.

Figure 1. Global confidence in police, all SCJS respondents

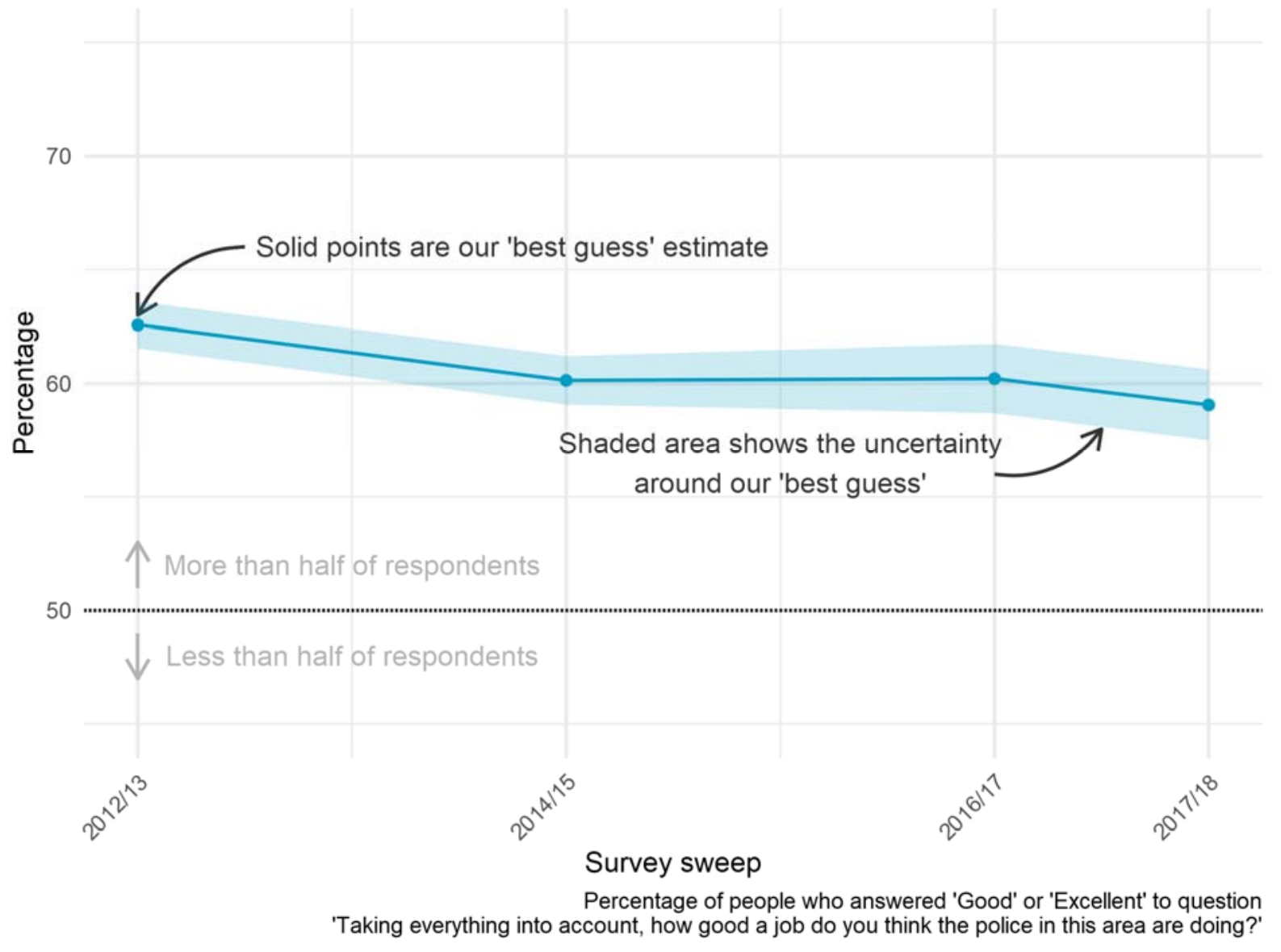




\section{Comparing trends in confidence in the police in Scotland with the rest of the UK}

Figure 2 compares levels of confidence in the police in Scotland to those reported in the equivalent crime surveys for England and Wales and Northern Ireland ${ }^{1}$. Levels of global confidence in the police in Scotland are very similar to those in England and Wales. For the 2017/18 sweep of SCJS and the comparable sweep from the Crime Survey for England and Wales (CSEW) these figures are essentially the same. Prior to this, global confidence in the police in Scotland was slightly lower than in England and Wales (around 60\% compared to roughly 62\%). Confidence in the police in Scotland and England and Wales is consistently higher than in Northern Ireland, which is just above 50\%.

\footnotetext{
${ }^{1}$ Intervals are calculated by the authors in different ways for all three surveys based on the data available. They should only be taken as indicative, and not used to make strict statistical inference. Northern Ireland Crime Survey (NICS) confidence intervals were calculated without taking into account survey design, and so may be underestimates. The Office of National Statistics (ONS) official release covering confidence in the police (ONS, 2020) uses a different survey question to the comparable question we report on here. ONS consistently reports higher levels of confidence in the police than the questions used here (around 75\% compared to just over 60\%).
} 
Figure 2. Global confidence in police, all SCJS, CSEW and NICS respondents

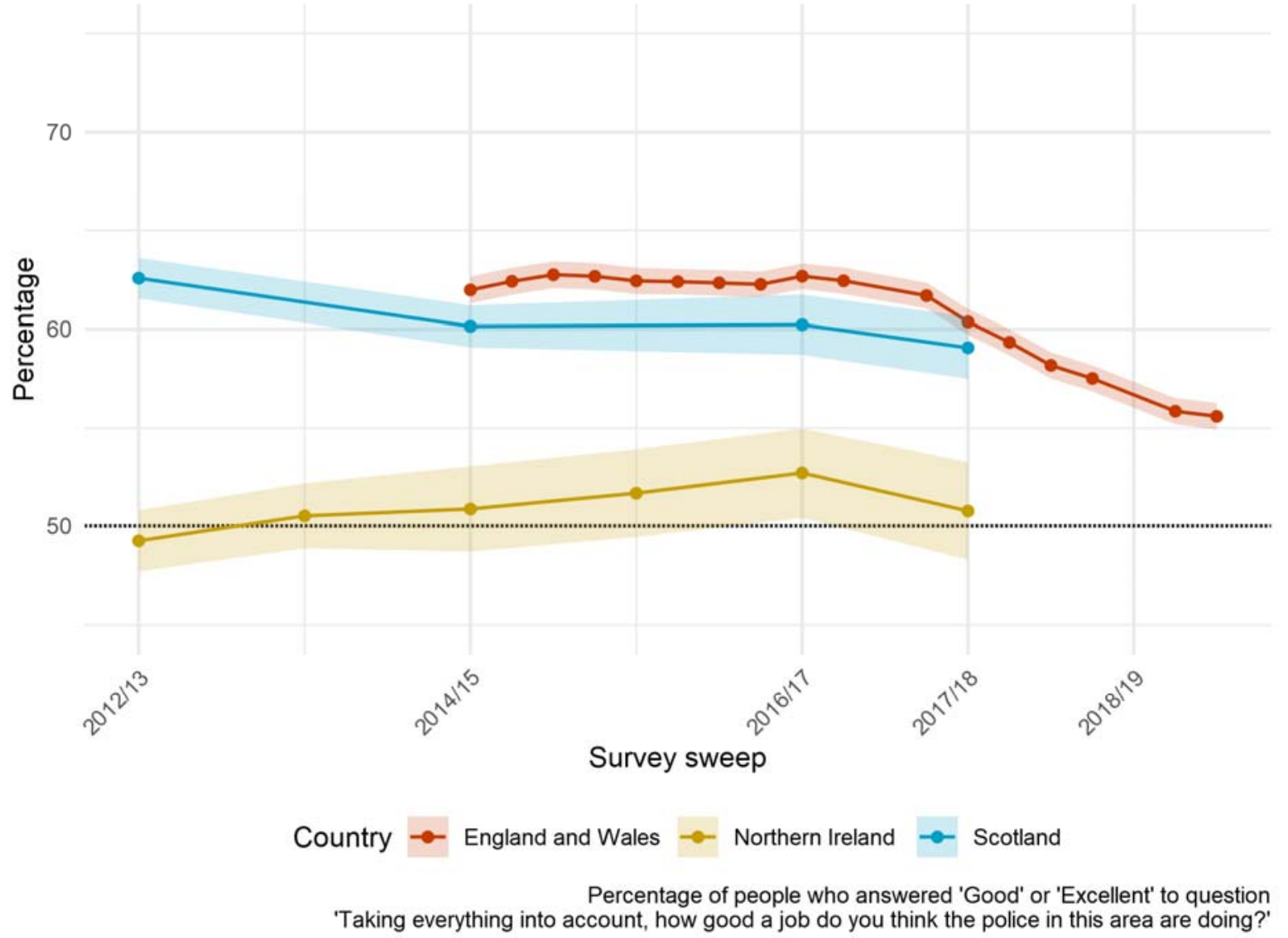

More recent data are available for England and Wales than Scotland $\mathrm{d}^{2}$, and these show a substantial decline in confidence in the police in England and Wales from the middle of 2017. Data from the 2018/19 SCJS are due to be published in June 2020, at which time it will be evident whether or not a similar drop can be seen in Scotland.

\section{Five year trend in overall confidence among victims}

Using the same format as Figure 1, Figure 3 shows trends separately for those who did and did not report being victims of a crime in the SCJS3.

Comparing global confidence amongst victims of crime to global confidence in non-victims, we see contrasting levels and trends. Non-victims have consistently had higher confidence

${ }^{2}$ Crime Survey for England and Wales publish quarterly rolling estimates of survey outcomes, including confidence in the police.

${ }^{3}$ As per the Scottish Government definitions of survey crime, this excludes Sexual offences or threats, and crimes that are considered out of scope for SCJS (such as offences committed outside Scotland, see Scottish Government, 2019) 
in the police than victims, but there is evidence of a decline from around 65\% in 2012/13 to around $60 \%$ in $2017 / 18$. In contrast, there is no evidence of any decline in global confidence amongst victims of crime which hovers at around $50 \%$.

The confidence in police estimate for victims has wide confidence intervals, particularly in $2016 / 17$ and 2017/18. This is a function of both changes to the survey design of the SCJS (which moved from a sweep every two years with 12,000 respondents to an annual sweep with around 6,000 respondents), and a fall in the number of people who were victims of crime. Both factors make it difficult to accurately detect any trend in confidence in the police amongst victims of crime from the SCJS.

Figure 3. Global confidence in police by victim/non-victim

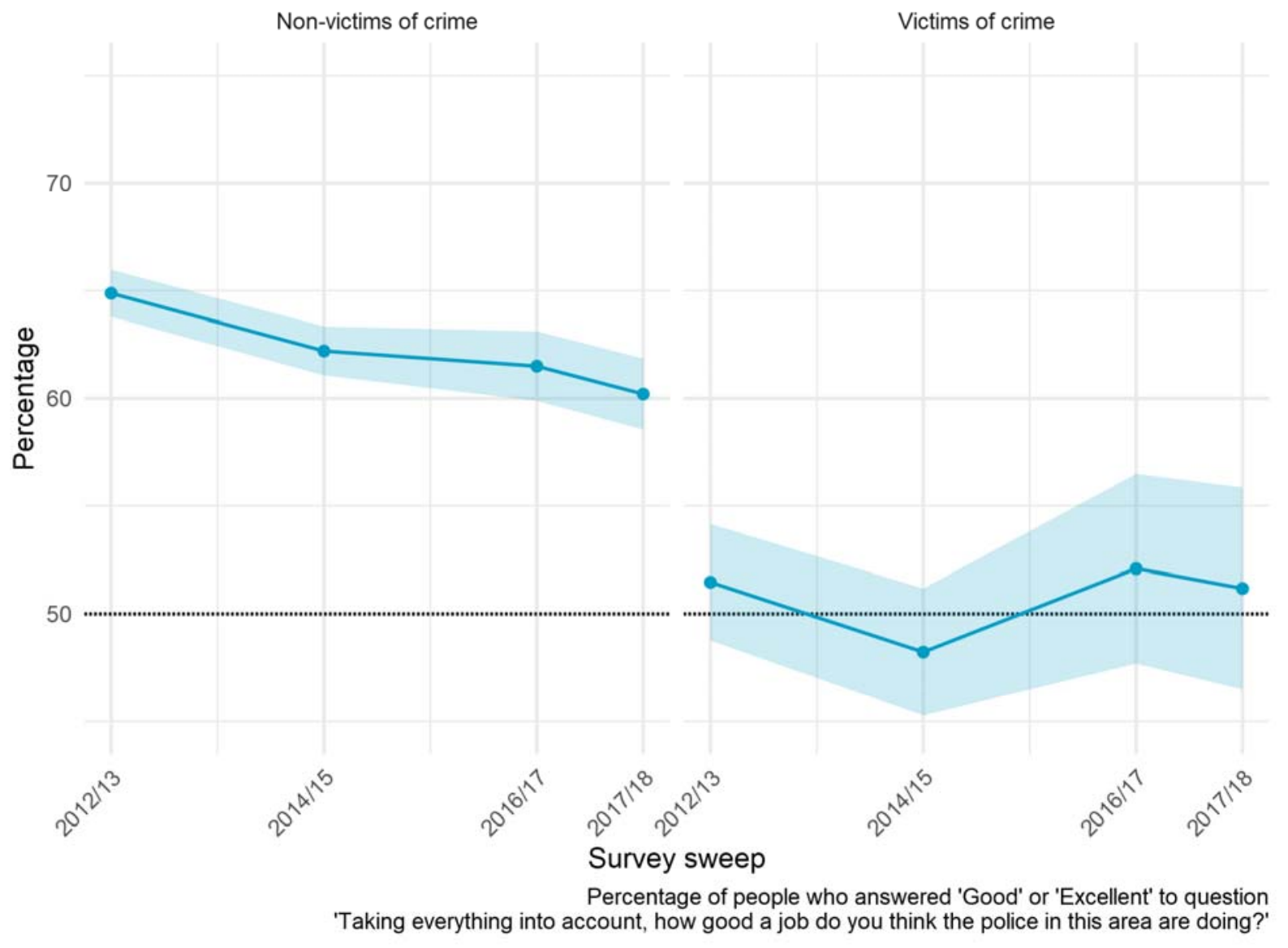

\section{Five year trend in overall confidence by area deprivation}

Figure 4 shows trends in global confidence in the police comparing SCJS respondents who live in the 15\% most deprived neighbourhoods in Scotland with other respondents.

Confidence tends to be higher amongst those who do not live in the $15 \%$ most deprived areas in Scotland, but this declined from around 64\% in 2012/13 to 60\% in 2017/18. 
Around 55\% of those living in one of the $15 \%$ most deprived neighbourhoods in Scotland report being confident in the police, with little evidence of change over time.

This contrast is similar to that between victims and non-victims of crime; there is a decline in confidence amongst the group with higher confidence in $2012 / 13$, but little evidence of a decline amongst the group with lower confidence.

Figure 4. Global confidence in police by area deprivation

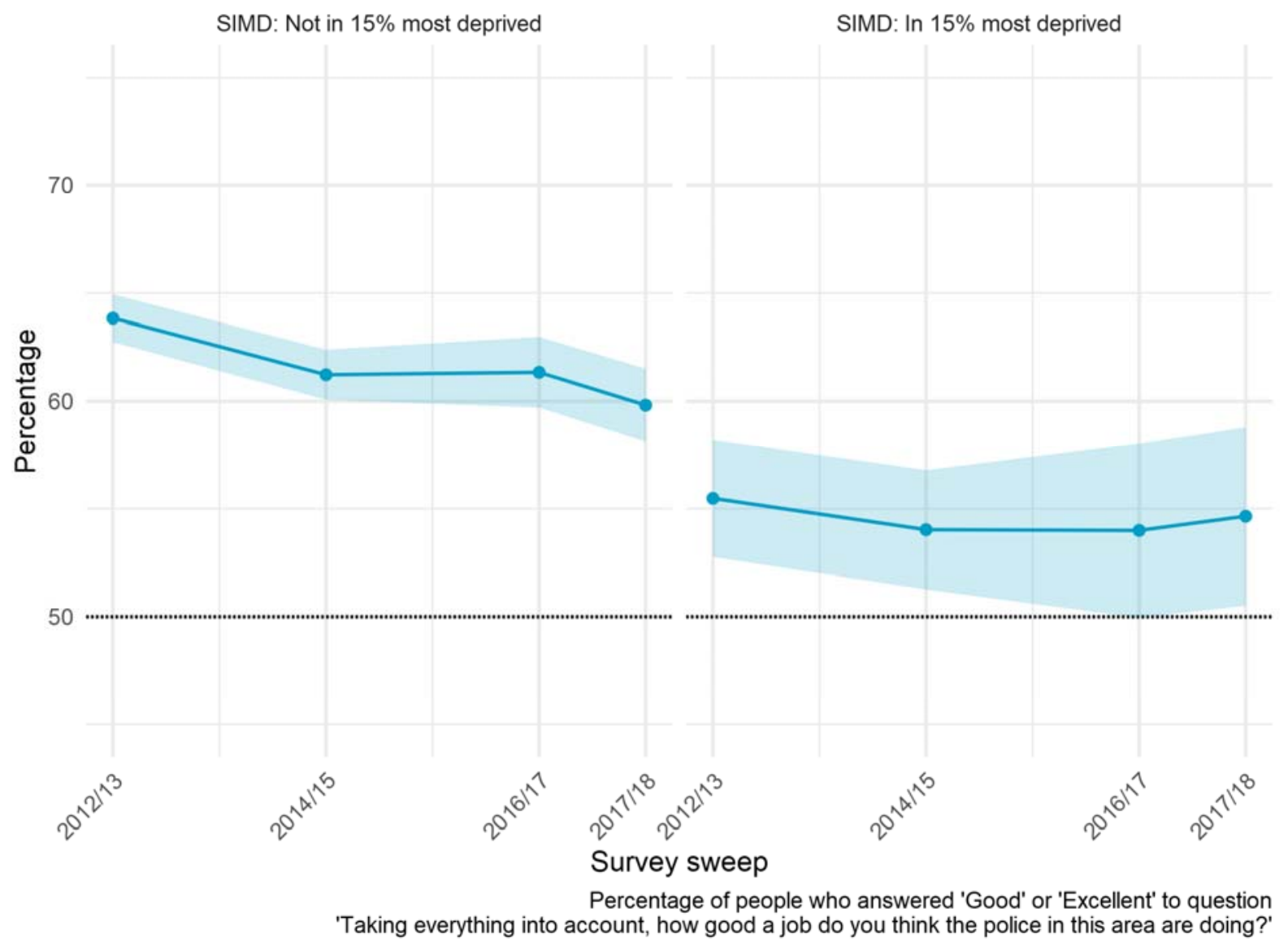

\section{Five year trend in overall confidence by age group}

Figure 5 shows trends in global confidence in the police by age group. The most striking trend is the fall in confidence amongst the over 65s, from around 68\% in 2012/13 to around $58 \%$ in $2017 / 18$. This means that the over $65 \mathrm{~s}$ went from being the most confident in the police to having a similar level of confidence to the other age groups. 
There is also evidence of a reduction in confidence amongst those aged 45-64 between 2012/13 and 2016/17; however, no evidence of any change amongst 25-44 year olds 4 .

The trend amongst those aged 16-24 appears very flat; however, the small sample sizes in the 2016/17 and 2017/18 sweeps of the survey mean that the confidence intervals around our estimates of confidence in the police for this age group are very wide (from around $55 \%$ to $75 \%$ ). Further analysis of this age group could only be done by combining sweeps of data together, which would lose information about trends, or by combining age groups together.

Figure 5. Global confidence in police by age

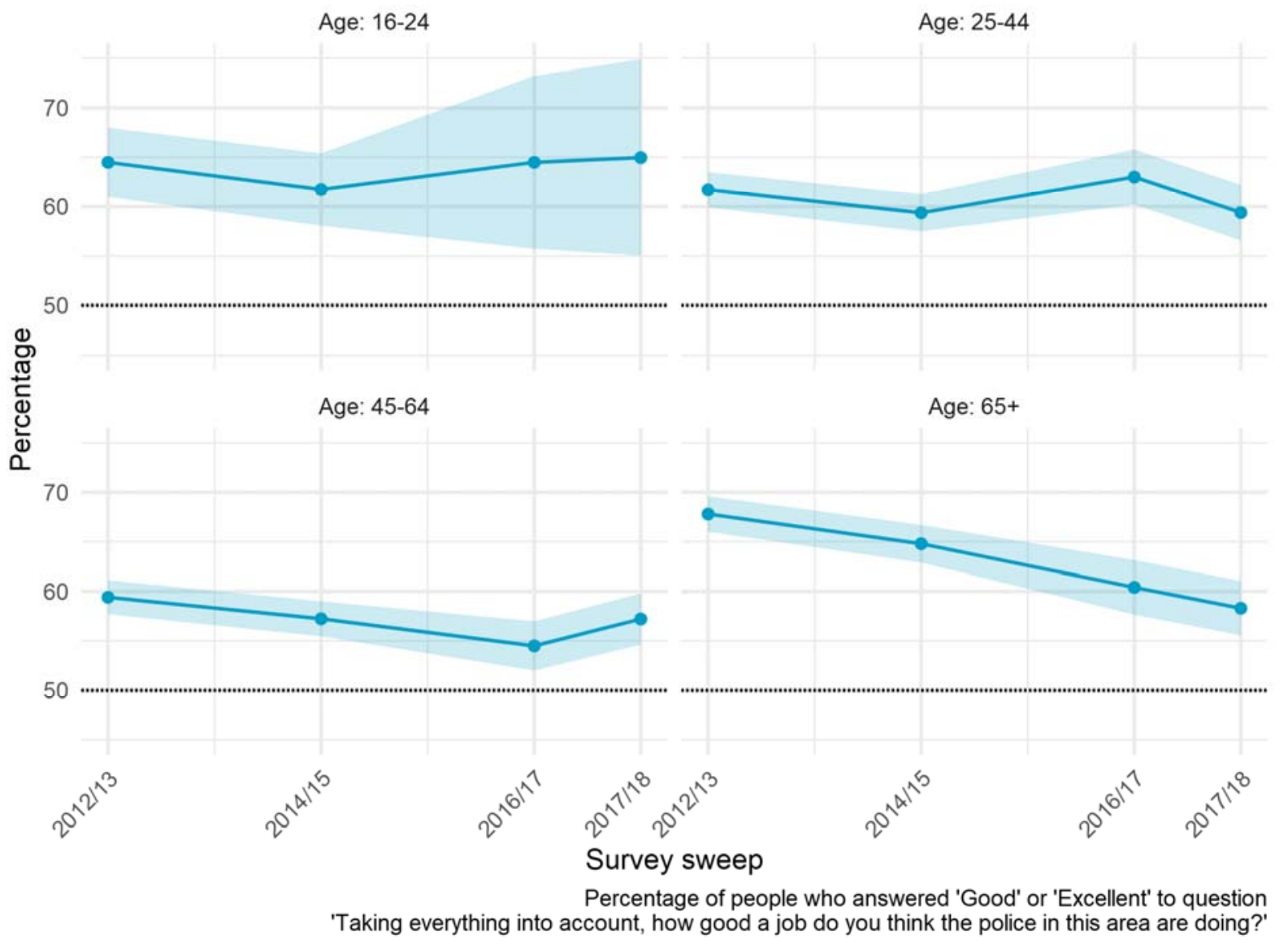

\footnotetext{
${ }^{4}$ Formal statistical testing of the difference in levels of confidence between 2012/13 and 2017/18 for those aged 25-44 and 45-64 did not show a 'statistically significant' different at standard 0.05 levels, meaning that there is not clear evidence of change over this period.
} 


\section{Five year trend in overall confidence by sex}

Figure 6 shows confidence in the police for male and female survey respondents ${ }^{5}$. Overall, women were more likely to display confidence in the police than men across all survey sweeps.

There was a clear and sustained decline in confidence in the police over time for men (from around $61 \%$ in $2012 / 13$ to roughly $56 \%$ in $2017 / 18$ ).

Amongst women there was a very slight decline, from around $64 \%$ being confident in the police in 2012/13 to around 62\% in 2017/18; however, this finding was only just statistically significant ${ }^{6}$.

Figure 6. Global confidence in police by sex

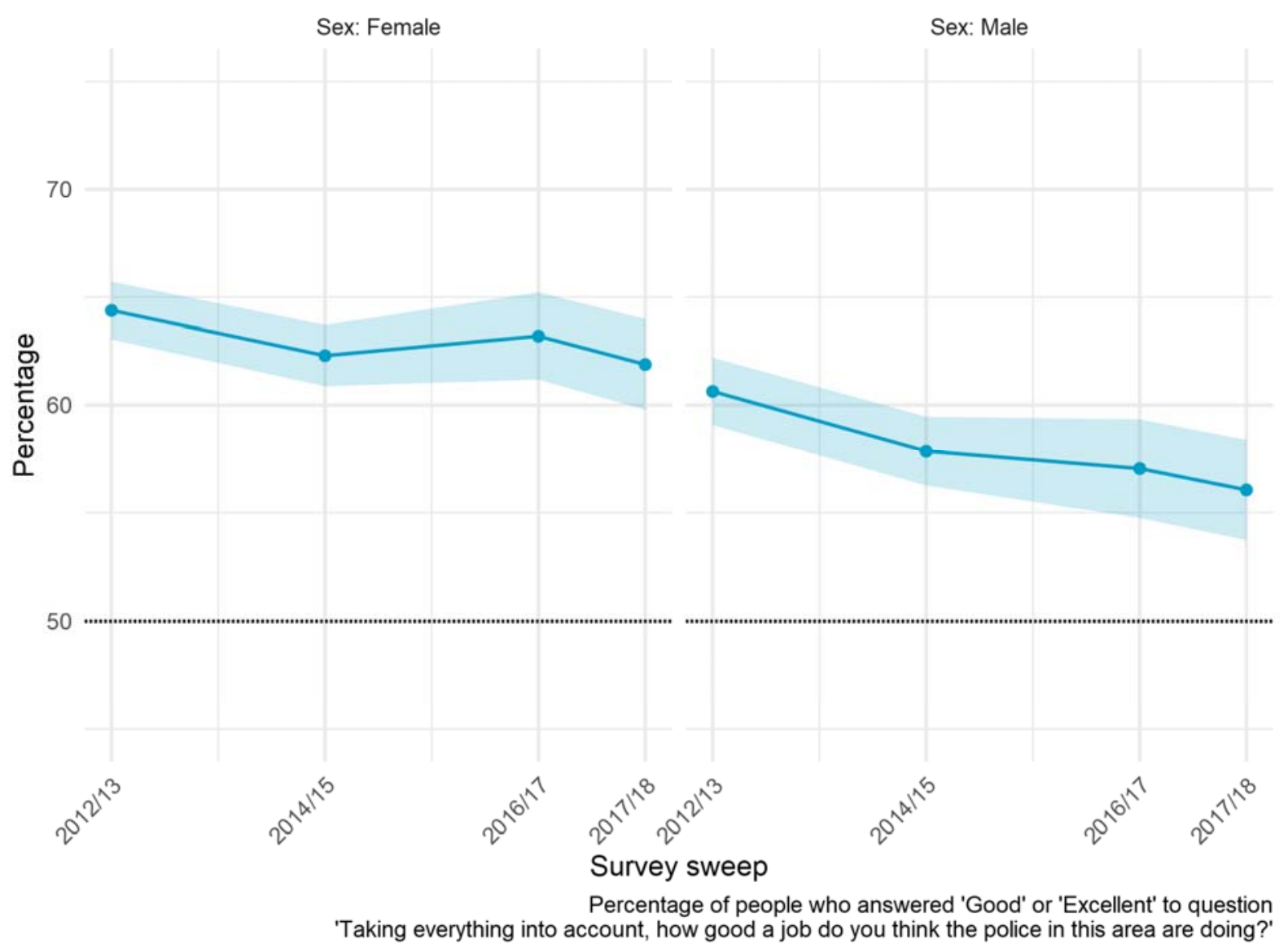

${ }^{5}$ This is based on responses to the question "Are you [the respondent] male or female?"

${ }^{6}$ Statistical significance testing of the difference in confidence in the police for women between 2012/13 and $2017 / 18$ was also ambiguous, with the estimated p-value lying exactly on the typical threshold of 'significance' at 0.05 . This means that we should treat this small decline in confidence for women with caution. 


\section{Five year trend in overall confidence by Command Area}

Figure 7 shows the estimate of public confidence in the police broken down by Police Scotland Command Area. SCJS respondents in the West had consistently lower confidence in the police than those in the North and East. The trend in the West showed no real change over time, remaining at around $57 \%$.

In the East, the trend in public confidence in the police shows a strong and consistent decline, from around $67 \%$ in $2012 / 13$ to just less than $60 \%$ in $2017 / 18$. This difference is highly statistically significant.

There was also a significant decline in confidence in the police in the North between 2012/13 and 2014/15; however, it remained stable from 2014/15 onwards.

It is notable that there was a large fall in public confidence in the police in the North and East Command Areas, but not the West, immediately after the creation of the single police force in 2013. This is in line with results of analysis of the Scottish Social Attitudes Survey between 2012 and 2015 (Murray 2018).

Figure 7. Global confidence in police by Police Scotland Command Area

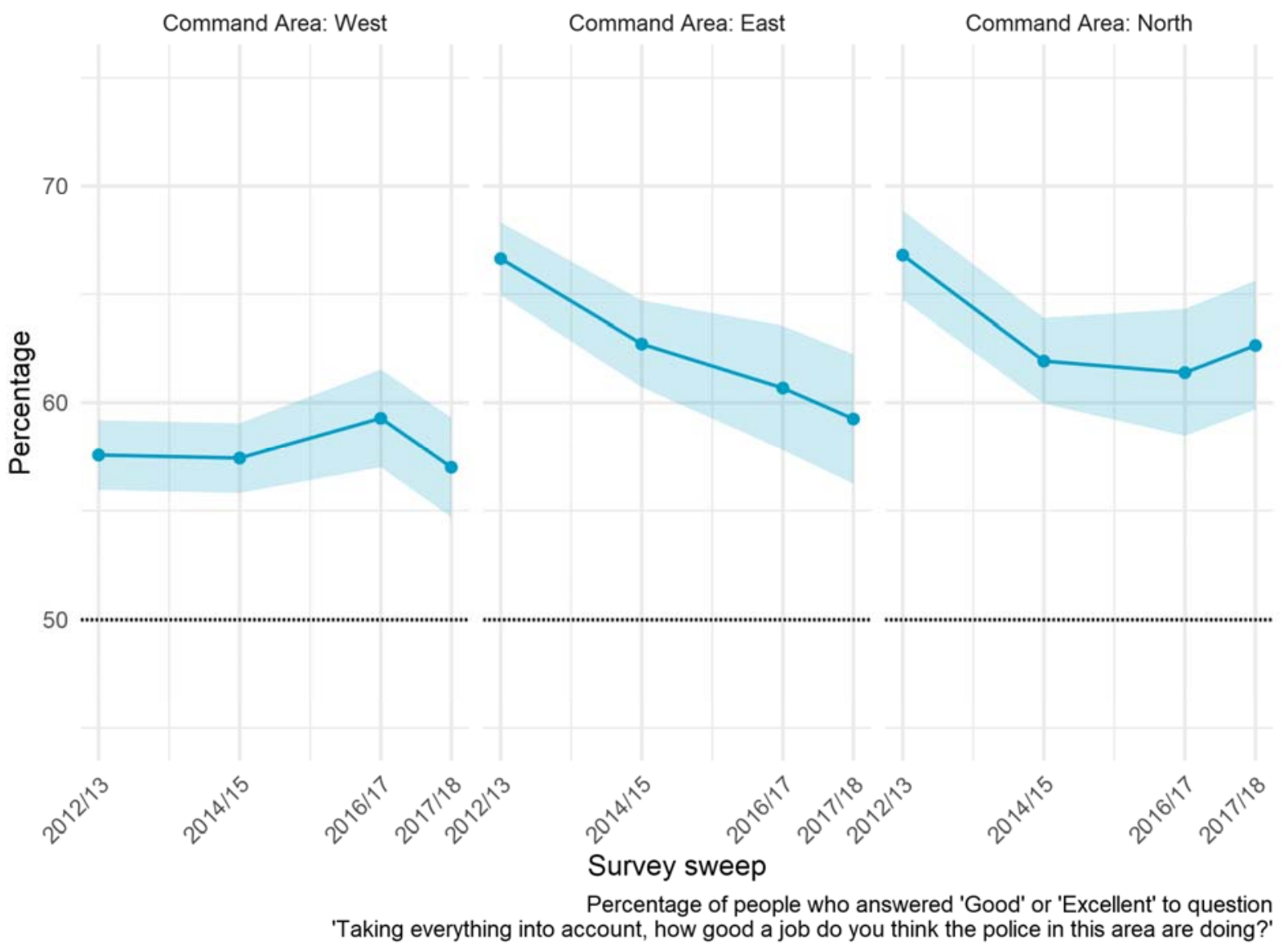


The overall difference in level of public confidence between Police Scotland Command Areas may be due to differences in policing styles, or they could be a consequence of differences in the demographic profile of people living in these areas.

While we can say that a lower percentage of people living in the West seem to have lower confidence in police in their local area, compared to those living in the other Command Areas, we cannot say that this is because they live in West region. For example, the lower reported confidence in the West may be due to higher average levels of deprivation. As shown in Figure 7, around 23\% of SCJS survey respondents (across all sweeps) in the West lived in the 15\% most deprived neighbourhoods in Scotland, whilst fewer than $10 \%$ of respondents in East and North regions did.

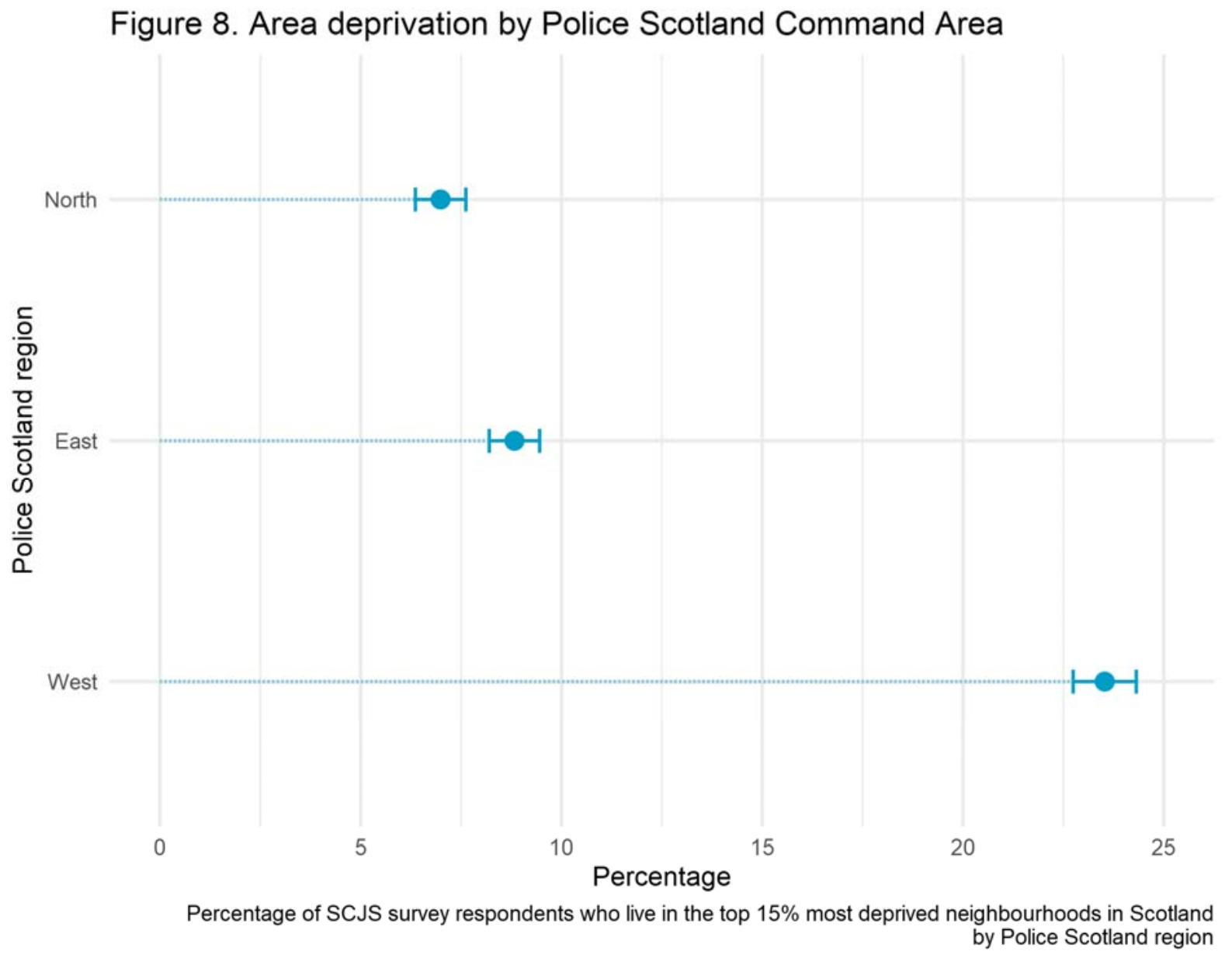

\section{Going deeper: Five year trend in overall confidence in the police by age and victim status for the three Command Areas}

Figure 9 shows the estimate of public confidence in the police broken down by Police Scotland Command Area and respondent age. This shows the problems that we encounter when trying to understand trends in confidence in the police using combinations of 
characteristics, as there is a lot of uncertainty around the estimates for each pairing of age group and region.

We can conclude that there is a consistent downwards trend for those aged 65+ in the West and East Command Areas. The North area also follows this trend until the last survey sweep, when there is an uptick. We do not however, have strong evidence that confidence in the police amongst the over 65s living in the North increased between 2016/17 and $2017 / 18$.

We can also conclude that for ages 16-44 and 45-64 levels of global confidence in the police area more similar across regions in 2017/18 than they were in 2012/13. This follows the trend we saw in Figure 7, with declines in confidence in the police in East and North Command Areas, with far less evidence of change in the West.

Figure 9. Global confidence in police by age and Command Area

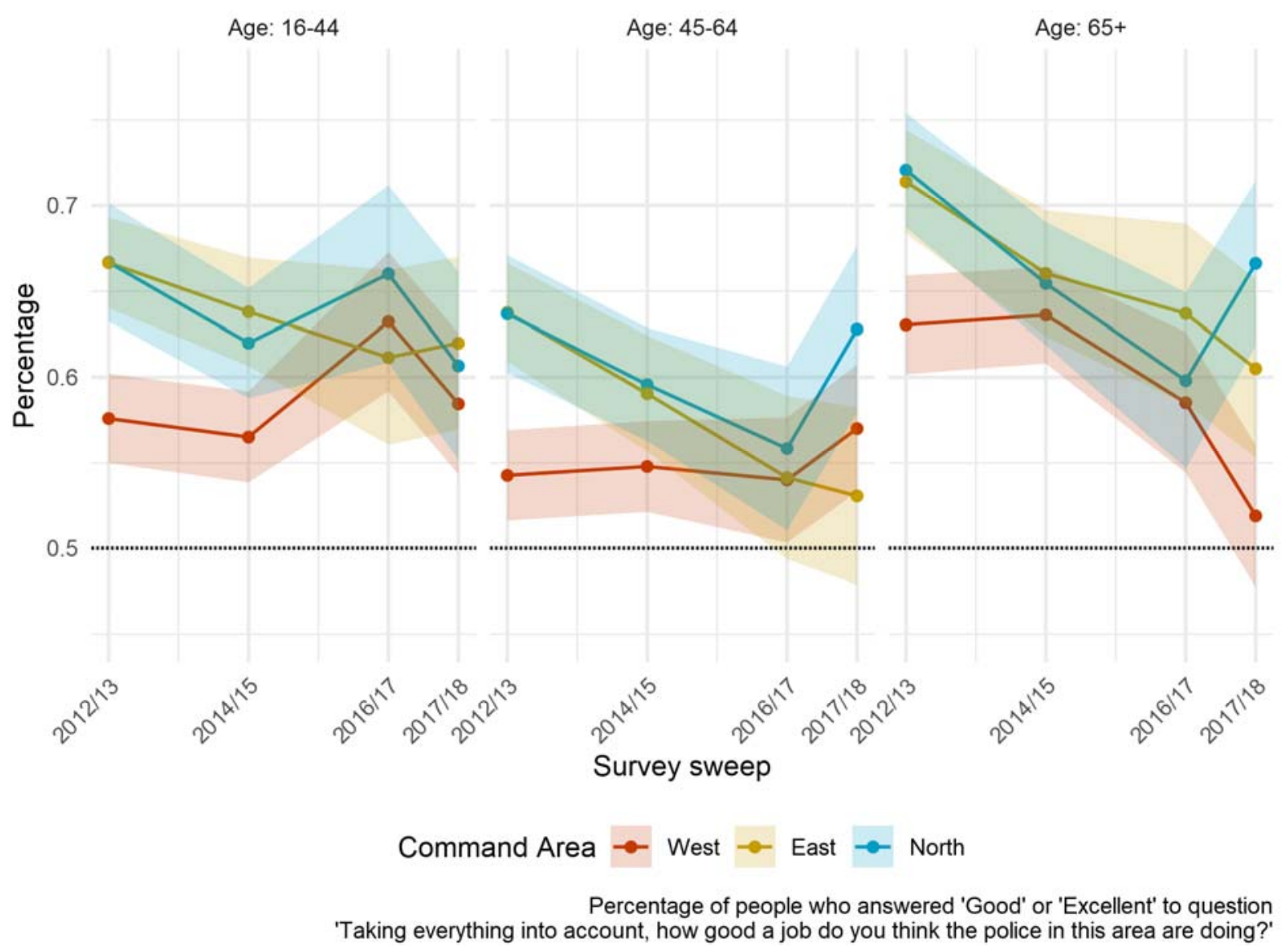

We repeated the same procedure for Command Area and victim status, as shown in Figure 10. Note that there is considerable uncertainty around the estimates of confidence in the police for victims of crime within each region the results, which again is indicative of the difficulties encountered when using combinations of characteristics. This arises because victimization is very rare in the SCJS, and increasingly so; around $17 \%$ of SCJS respondents were victims of crime in 2012/13, reducing to around $13 \%$ in $2017 / 18$. As a result, it is 
harder to provide a precise estimate of victims' confidence in the police over time, as more recent sweeps report fewer victims of crime.

The SCJS can give a more precise estimate of global confidence in the police amongst nonvictims of crime than among victims. As a result we can conclude that the overall regional trends shown in Figure 7 is repeated amongst non-victims, with evidence of declines in confidence in the police in East and North Command Areas, and far less evidence of change in confidence in the police amongst non-victims in the West. This reflects the fact that the majority of SCJS respondents are not victims of crime, and so the level of confidence in police for all SCJS respondents together is closer to that for non-victims than it is for victims.

Figure 10. Global confidence in police by victimization and Command Area

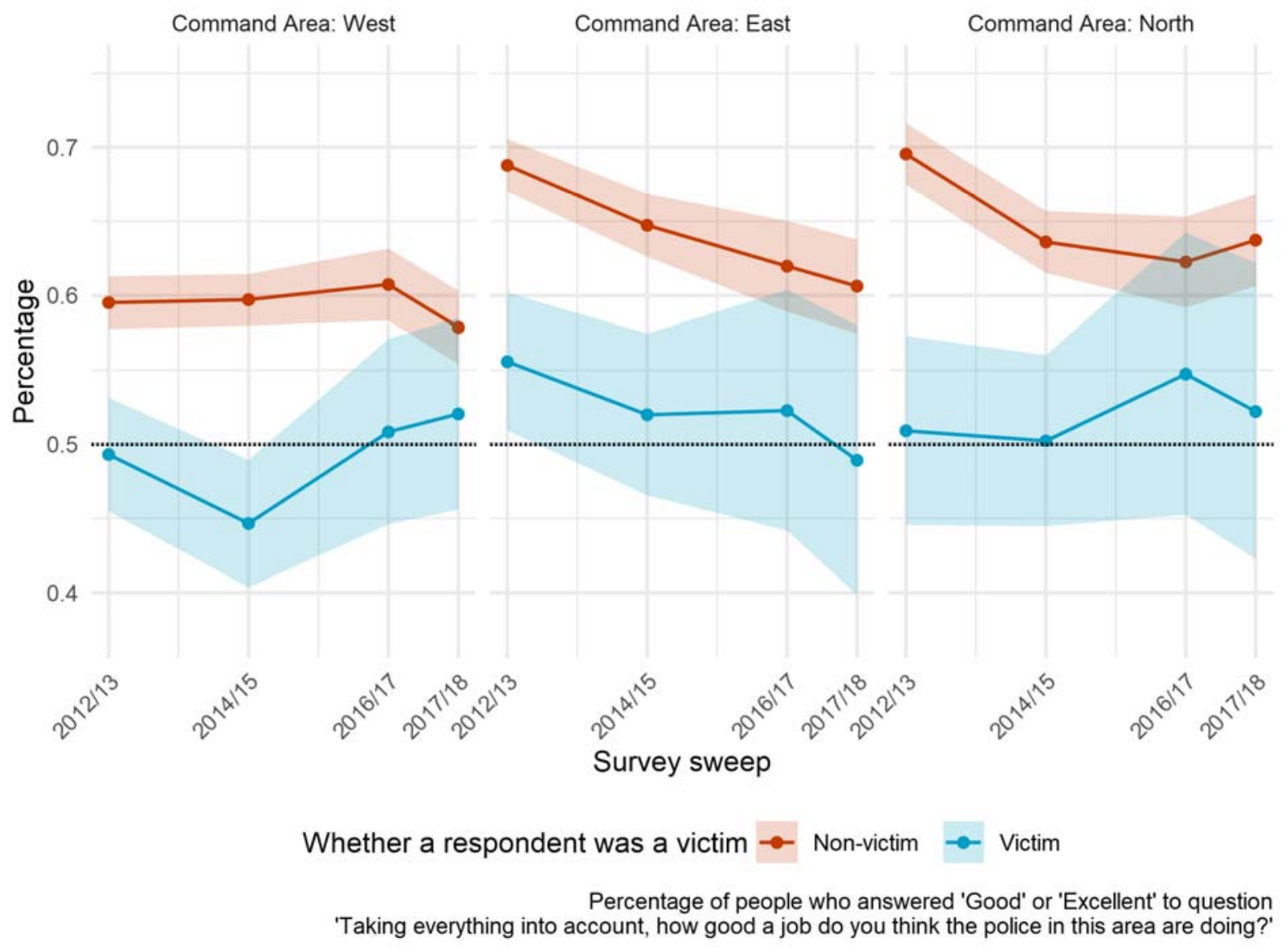

\section{Conclusions and outstanding questions}

This report has presented a high-level analysis of trends in a 'global' measure of public confidence in the police in Scotland between 2012/13 and 2017/18. Based on this analysis we can conclude that global confidence in the police in Scotland is at a similar level to that in England and Wales, and higher than that in Northern Ireland. More people in Scotland 
are confident in the police than not (around 60\% in total); however, there was a decline in global confidence in the police in Scotland between 2012/13 and 2017/18. The largest period of reduction occurred between 2012/13 and 2014/15, which coincides with the introduction of the new Police Service of Scotland and may be, at least in part, related to a period of controversy around Scottish policing that occurred at this time. The downward trend in Scotland does contrast with a broadly increasing trend in Northern Ireland; however, there have also been substantial declines in confidence in the police in England and Wales, albeit more recently.

We can also conclude that confidence in the police is not equally spread across the population. It tends to be higher amongst women, older people, those who have not recently been victims of crime, those who do not live in the most deprived communities, and those living in the North and East of Scotland. However, there have been changes over time in the level of public confidence amongst these groups, such that those who were the most confident in the police in 2012/13 have shown a significant reduction in confidence, whereas confidence amongst those who were already least confident has remained fairly stable.

We have identified a particular area of concern relating to the decline in confidence amongst those aged 65 or over. This suggests that more needs to be done to boost the confidence of older people in order to restore their faith that the police are doing a good job in their local area. This pattern is evident across all three Command Areas, suggesting that a national strategy may be required to boost confidence amongst older people.

We have also identified geographical variation, with those living in the East and North Command Areas showing much greater loss of confidence. Confidence amongst those living in the West of Scotland did not decline over time; however, it was already much lower amongst those living in these areas. Again, this suggests that Police Scotland may need to develop a national strategy that aims to restore public confidence amongst people living in the North and East of Scotland while, at the same time, taking steps to build up confidence amongst those in the West.

This analysis cannot tell us why confidence in the police has declined, or give much more detail about the groups amongst whom confidence has fallen. Sub-dividing the data any further than we have in this report, such as looking at confidence in the police amongst female non-victims aged over 65 across each Police Scotland region, would reduce our capacity to make robust inferences from the data. This could be overcome to some extent by combining sweeps of the data together (although this would lose the ability to examine change over time) or using statistical modelling which would add complexity to the analysis and interpretation of the data.

Whilst we saw a lack of evidence of a decline in confidence in the police amongst victims of crime and amongst those living in Scotland's most deprived communities, the overall lower levels of confidence in the police amongst these groups is concerning. Moreover, absence of evidence is not evidence of absence, and the fact that both victimization (at between 20 and $15 \%$ of SCJS) and living in one of Scotland's 15\% most deprived neighbourhoods (by 
definition, likely to be around 15\%) mean that the SCJS provides less certain estimates of confidence in the police for these groups as they form a minority of respondents.

Additional statistical modelling using the SCJS, or data collection focusing on these groups in particular, may shed further light on confidence in the police amongst victims of crime and those living in Scotland's most deprived communities. 


\section{Appendix}

\section{Measuring confidence in the police}

Measuring confidence in the police is complicated, because this concept has many aspects. The simplest approach is to pick a single survey question as an indicator of confidence in the police, typically a 'global measure' of 'overall trust and confidence'. This is the approach we have adopted in this report, and in SCJS this is the answer to the question "Taking everything into account, how good a job do you think the police in this area are doing?". Bradford and Jackson, experts in the study of confidence in the police, are "broadly convinced... that easy to understand global measures are useful for policy-makers and others" (2019:55). Using just a single 'global' measure of confidence in the police emphasises simplicity over accuracy; whilst single indicator measures "can summarize global attitudes to an extent, they will always be somewhat crude and reductive" (Myhill et al. 2011:121). This approach is thought to be "crude and reductive" because:

1. There are different aspects of public attitudes to the police which feed in to overall trust and confidence. Bradford and Jackson (2019:27) identify seven related concepts: Satisfaction with police contact, Procedural Justice (police treat people with respect), Distributive Justice (police provide the same quality of service to all citizens), Community Engagement (deal with things that matter to people in a given local area), Bounded Authority (respecting the limits of one's rightful authority), Effectiveness (how well police respond to incidents), Legitimacy (whether people generally support how the police act), and Willingness to Cooperate.

2. As a result, in the general population 'global' confidence in the police may not relate to actual police activity at all, but to people's feelings towards the institution of the police in general, particularly for people who have not had recent contact with the police (Myhill et al. 2011:115).

3. Because the number of people who are victims of crime in Scotland has declined over time, to get reliable estimates of confidence in the police in Scotland among victims of crime might require either: pooling survey sweeps together, making this a coarser measure of change over time; or making estimates for each year based on a more sophisticated statistical model. Neither of these approaches are that well-suited to measuring change over time in short increments.

\section{SCJS questions about confidence in the police}

Table 1 shows the sweeps in which the SCJS has asked about confidence in or attitudes towards the police, the aspects of confidence asked about and what percentage of the respondents were asked. 
Table 1: Aspect of confidence (\% survey asked)

\begin{tabular}{crrr}
\hline Sweep & $\begin{array}{r}\text { Effective } \\
\text { ness }\end{array}$ & $\begin{array}{r}\text { Legitima } \\
\text { cy/fairne } \\
\text { ss }\end{array}$ & Global \\
\hline $2008 / 09$ & $100 \%$ & - & $25 \%{ }^{*}$ \\
$2009 / 10$ & $100 \%$ & $25 \%$ & - \\
$2010 / 11$ & $100 \%$ & $25 \%$ & - \\
$2012 / 13$ & $100 \%$ & $100 \%$ & $100 \%$ \\
$2014 / 15$ & $100 \%$ & $100 \%$ & $100 \%$ \\
$2016 / 17$ & $100 \%$ & $100 \%$ & $100 \%$ \\
$2017 / 18$ & $100 \%$ & $100 \%$ & $100 \%$ \\
\hline *2008/09 asked a different global confidence \\
question than 2012/13 onwards
\end{tabular}

The questions asked to measure these aspects of confidence in police are:

\section{Global confidence}

- $\quad$ "Taking everything into account, how good a job do you think the police in this area are doing?" (2012/13 onwards)

- "Taking everything into account, would you say the police in your local area do a good job or a poor job?" (2008/09, quarter sample module B)

\section{Effectiveness}

"How confident are you in your local police force's ability to:"

- "Prevent crime?"

- "Respond quickly to appropriate calls and information from the public?"

- "Deal with incidents as they occur?"

- "Investigate incidents after they occur?"

- "Solve crimes?"

- "Catch criminals?"

\section{Legitimacy/fairness: Community engagement}

"To what extent do you agree or disagree with the following statements about the police in your local area?"

- "Police in this area can be relied on to be there when you need them"

- $\quad$ "Police in this area are not dealing with the things that matter to people in this community"

- "The police in this area listen to the concerns of local people"

- "Community relations with the police in this local area are poor" 


\section{Legitimacy/fairness: Fairness}

"To what extent do you agree or disagree with the following statements about the police in your local area?"

- $\quad$ "Police in this area would treat you with respect if you had contact with them for any reason"

- "The police in this area treat everyone fairly regardless of who they are"

\section{Other}

- As well as the above questions about their own attitudes towards the police, SCJS respondents are asked about their perceptions of other people in their area's confidence in the police. This is measured via agreement with the statement "Overall, people have a lot of confidence in the police in this area." This is asked alongside the questions about community engagement and fairness (so for $25 \%$ of the sample in $2009 / 10$ and $2010 / 11$ and $100 \%$ thereafter). 


\section{References}

John Jackson, Ben Bradford, Measuring Public Attitudes Towards the Police, 2019, https://osf.io/preprints/socarxiv/2dh5s/

Andy Myhill, Paul Quinton, Ben Bradford, Alexis Poole, Gillian Sims, It Depends What You Mean by 'Confident': Operationalizing Measures of Public Confidence and the Role of Performance Indicators, Policing: A Journal of Policy and Practice, Volume 5, Issue 2, June 2011, Pages 114-124, https://doi.org/10.1093/police/par027

Kath Murray, Police reform and public confidence in Scottish policing: 2012 to 2015, 2018, http://www.sipr.ac.uk/Plugin/Publications/assets/files/SSA\%20_2012_2015_Public_confi dence_and\%20police\%20reform.pdf

Office of National Statistics, Confidence in the local police, 2020, https://www.ethnicityfacts-figures.service.gov.uk/crime-justice-and-the-law/policing/confidence-in-the-localpolice/latest

Scottish Government, Scottish Crime and Justice Survey 2017/18: Technical Report, March 2019, https://www2.gov.scot/Resource/0054/00547069.pdf 